\title{
Combination of computer vision and backscattering imaging for predicting the moisture content and colour changes of sweet potato (Ipomoea batatas L.) during drying
}

\begin{abstract}
This study seeks to investigate the potential of using combined computer vision (CV) and laserinduced backscattering imaging (LLBI) in monitoring the quality attributes of sweet potato during drying. $\mathrm{CV}$ and backscattered images of $4 \mathrm{~mm}$ thickness sweet potato slices were captured after every one-hour of drying, at drying temperatures of $50-70{ }^{\circ} \mathrm{C}$. Reference quality properties, such as moisture content, $\mathrm{L} * \mathrm{a} *$ and $\mathrm{b} *$ colour coordinates were measured hourly under the same drying conditions. Principal component analysis (PCA) and partial least square regression (PLS) were applied to the extracted combined CV (based on RGB) and backscattering imaging parameters to analyse the quality changes of sweet potato during drying. The results showed that there was significant effect of drying temperature and time on combined $\mathrm{CV}$ and backscattering imaging parameters. The combined optical method showed good correlation with moisture content and colour properties i.e $\mathrm{L} *$ and $\mathrm{a} *$ of sweet potato with $\mathrm{R} 2>0.7$. Specifically, the redness (a*) gave the highest coefficient of determination (R2) of 0.80 , while the moisture ratio (MR) showed the lowest root mean square error of validation (RMSEV) with the value of 0.18 . Thus, this study has shown that combined CV and backscattering imaging parameters can serve as a non-destructive tool for detecting the changes in quality parameters of sweet potato during drying.
\end{abstract}

Keyword: Drying; Digital imaging; Backscattering imaging; Sweet potatoes; Quality attributes 